\section{Improvement of In Vitro Culturing of Habanero Pepper by Inhibition of Ethylene Effects}

\author{
Nancy Santana-Buzzy, ${ }^{1}$ Adriana Canto-Flick, \\ Lourdes G. Iglesias-Andreu, María del C. Montalvo-Peniche, \\ Guadalupe López-Puc, and Felipe Barahona-Pérez \\ Unidad de Bioquímica y Biología Molecular de Plantas, Centro de Investigación \\ Científica de Yucatán. Calle 43 \#130, Chuburná de Hidalgo, Mérida, Yucatán, \\ 97200, México
}

Additional index words. Capsicum chinense, ethylene, plant abnormalities, silver nitrate, cobalt chloride, vitrification

\begin{abstract}
The in vitro production of ethylene and its effects on the development of Habanero pepper (Capsicum chinense Jacq.) plantlets were evaluated using nonventilated containers (NVCs) and ventilated containers (VCs). Shoots of Habanero pepper between 0.5 and $1.0 \mathrm{~cm}$ of height were cultivated in Magenta culture boxes and samples of the headspace atmosphere were taken every four days during the previously established culturing time of $\mathbf{4 0}$ days. The presence of ethylene was detected in the NVCs and produced a negative effect on the development of plantlets. In a second phase of this work, the effect of silver nitrate $\left(\mathrm{AgNO}_{3}\right)$ and cobalt chloride $\left(\mathrm{CoCl}_{2}\right)$ on ethylene production was evaluated during in vitro development of Habanero pepper plantlets. Concentrations of 50,300 , and $500 \mu \mathrm{M}$ of each ethylene inhibitor were used in the culture medium. Although cobalt chloride partially inhibited the production of ethylene during in vitro culture of this species, at low concentrations the plantlets presented some degree of vitrification and the highest concentration proved to be toxic for the plantlets. Silver nitrate added to the culture medium did not inhibit ethylene production, however, it did inhibit the effect of this hormone on the plantlets. In fact, when high concentrations of silver nitrate were used $(300 \mu \mathrm{M})$, high amounts of ethylene were detected in the headspace of the vessels and plantlets were actually healthier.
\end{abstract}

Ethylene $\left(\mathrm{C}_{2} \mathrm{H}_{4}\right)$, a simple olefin that exists in gaseous state under normal physiological conditions, is produced during in vitro plant tissue culture (Finkelstein et al., 1988). Production of $\mathrm{C}_{2} \mathrm{H}_{4}$ is associated with poor regeneration or recalcitrant behavior of culture materials (Chi and Pua, 1989; Chi et al., 1991; Mohiuddin et al., 1997; Pua and Chi, 1993). The role of ethylene in plant tissue culture is not clear; it may be able to change the morphogenic capacity of explants in vitro (Biddington, 1992).

The positive and negative effects of ethylene on the growth and development of in vitro cultured plants or organs have been described for several crops (Auboiron et al., 1990; Blankenship et al., 1993; Chi et al., 1990; Chraibi et al., 1991; Weeler et al., 2004).

It has been reported that, in Zea mays (Vain et al., 1989) and in barley (Cho and Kasha, 1989) the ethylene formed during in vitro culture enhanced the production and regeneration of embryogenic calluses. In tobacco, ethylene favored the development of floral buds. However, in other studies, ethylene production by in vitro grown shoots in sealed containers,

Received for publication 7 Oct. 2005. Accepted for publication 27 Nov. 2005. The authors wish to thank Mr. Julian Coello for technical assistance and Sergio Peraza for helping with English corrections.

${ }^{1}$ To whom reprint requests should be addressed; e-mail buzzy@cicy.mx. has been observed to inhibit plant regeneraand cell differentiation (Chraibi et al., 1991) as well as affecting general plant growth and development (Pua, 1993).

The addition of chemicals such as cobalt chloride or silver nitrate, which can inhibit ethylene production (Mohiuddin et al., 1995; Palmer, 1992; Pua and Chi, 1993) or its function by blocking certain steps in the pathway of ethylene biosynthesis (Pua, 1993), have shown to be effective in overcoming the recalcitrance or in enhancing regeneration.

The first protocol for Habanero pepper regeneration was recently reported by Santana et al. (2005), as a part of an in vitro conservation, micropropagation and genetic improvement project. Nevertheless, in regard to the sensibility of this species to ethylene and the recalcitrance of the pepper genus, the objective of this work was to evaluate the Habanero pepper shoot development cultivated under different conditions: in ventilated (VC) and nonventilated containers (NVC) and to determine the effect of silver nitrate $\left(\mathrm{AgNO}_{3}\right)$ and cobalt chloride $\left(\mathrm{CoCl}_{2}\right)$ on ethylene production and shoot development during in vitro culturing of this species.

\section{Materials and Methods}

Plant tissue culture. Aseptic plantlets of Habanero pepper var. Nux, were used to tion from callus (Robinson and Adams, 1987) carry out the experiments. This plant was selected as it is apparently the only regional variety of orange Habanero pepper (Capsicum chinense) known and is also the most popular with consumers and the industry. The fruit is extremely pungent and orange color (as the name indicates). However, like most of the plants of this species, it is susceptible to a number of environmental factors, both biotic and abiotic. Therefore, seeds of this cultivar were surface sterilized and germinated following the protocol established by Santana et al. (2005). After $30 \mathrm{~d}$ of culture, the plantlets were dissected and single node cuttings were cultured with different treatments. The culture medium was MS salts (Murashige and Skoog, 1962), supplemented with myo-inositol (554.9 $\mu \mathrm{M})$, thiamine- $\mathrm{HCl}(29.64 \mu \mathrm{M})$, sucrose $3 \%$ $(\mathrm{w} / \mathrm{v})$ and gelrite $0.22 \%(\mathrm{w} / \mathrm{v})$, without growth regulators. All media were adjusted with $\mathrm{NaOH}$ to $\mathrm{pH} 5.8$ and autoclaved at $1.1 \mathrm{~kg} \cdot \mathrm{cm}^{-2}\left(121^{\circ} \mathrm{C}\right)$ for $15 \mathrm{~min}$. Four explants (single node cuttings) were cultivated per magenta box containing $40 \mathrm{~mL}$ of MS medium. Each Magenta box was provided with a septum in the lid so that samples from the inner atmosphere could be withdrawn with a sterilized syringe every $4 \mathrm{~d}$ to determine ethylene concentrations inside the culture vessels. This method allowed us to sample the same boxes throughout the whole experiment. The cultures were incubated at $26 \pm$ $2{ }^{\circ} \mathrm{C}$ in continuous light $\left(40\right.$ to $\left.50 \mu \mathrm{mol} \cdot \mathrm{m}^{-2} \cdot \mathrm{s}^{-1}\right)$, over $60 \mathrm{~d}$. Three Magenta boxes were used for each treatment.

Ethylene measurements. To determine ethylene concentrations, 2-mL samples of headspace atmosphere were withdrawn from each Magenta box by means of a syringe. The ethylene was measured by gas chromatography, using a chromatograph (8690 Series II; Hewlett Packard) under the following conditions: column was a GS-Q FSOT (Alltech, $30 \mathrm{~m} \mathrm{~L}$ $\times 0.53 \mathrm{~mm}$ ID), nitrogen was the carrier gas at a flow rate of $10 \mathrm{~mL} \cdot \mathrm{min}^{-1}$; oven temperature was $70^{\circ} \mathrm{C}$, injector and detector temperatures were $200^{\circ} \mathrm{C}$, pure ethylene was used as external standard, retention time for ethylene peak was 2.2 min with a FID detector.

Ethylene measurements in nonventilated containers (NVCs) and ventilated containers (VCs) during in vitro culture of Habanero pepper. To verify if there was any accumulation of ethylene inside the culture vessels and if the presence of this gas-regulator had any effect on the development of Habanero pepper shoots and plantlets cultivated in vitro, an experiment was carried out using Magenta boxes that allowed gas exchange with ambient atmosphere (VCs) through a hole made in the lid and covered with filter paper (Whatman No. 41) to avoid contamination. Magenta boxes with complete lids were used as nonventilated containers (NVCs). For each experiment, 4 Magenta boxes were used and four shoots 0.5 to $1.0 \mathrm{~cm}$ long were cultured per Magenta box. Samples from the headspace of the Magenta boxes were taken every 4 d over a culture period of $40 \mathrm{~d}$. In these experiments, shoot growth and development were determined by measuring fresh weight, plantlet height and number of fully developed leaves. Other characteristics 
observed during this experiment were related to the development and quality of the plantlets: vigor, general color, leaf senescence, degree of vitrification, presence of callus or other abnormalities.

Effect of silver nitrate $\left(\mathrm{AgNO}_{3}\right)$ and cobalt chloride $\left(\mathrm{CoCl}_{2}\right.$ ) on ethylene production during in vitro culture of Habanero pepper shoots. The effect was evaluated using different concentrations $(50,300$ and $500 \mu \mathrm{M})$ of each inhibitor in the culture medium, including a control. Media formulation was the same as in previous experiments with the addition of the ethylene inhibitors. Both ethylene inhibitors were added to the media before autoclaving. Sampling was conducted as previously described and plantlet development was evaluated for each treatment. Data were analyzed by analysis of variance (ANOVA) using SigmaStat V.1.

\section{Results}

Ethylene measurements in NVCs and VCs during in vitro culture of Habanero pepper. Ethylene was not detected during in vitro culture of Habanero pepper shoots in ventilated containers. Culture time was 40 days, as shown in Fig. 1. In nonventilated containers, however, ethylene production was evident from the 16th day of culture; accumulation proceeded gradually until day 20 of culture $\left(0.02 \mu \mathrm{L} \cdot \mathrm{L}^{-1}\right)$ and then a peak concentration of $0.12 \mu \mathrm{L} \cdot \mathrm{L}^{-1}$ was reached between days 24 and 28. Thereafter, the ethylene concentration rapidly decreased and remained between 0.02 and $0.03 \mu \mathrm{L} \cdot \mathrm{L}^{-1}$ from day 32 until the end of the culture time.

In a recent study with different types of Habanero pepper explants cultivated in NVCs, without growth regulators, Santana etal. (2005) observed some growth abnormalities as a result of culture conditions and possibly due to a high sensibility of this species to the ethylene that accumulated within the culture vessel.

In this work it was possible to observe the differences in the development of shoots grown in VCs and in NVCs. The explants cultivated in NVCs often showed formation of prominent nodules and roots (Fig. 2a) and callus formation at the explant abscission zone (Fig. 2b). Under these conditions, plantlets that were able to grow showed callus formation along the stem, initially looking like a cotton web or mesh (Fig. 2c) sometimes becoming a compact callus. This phenomenon could be observed on roots, leaf surface and plantlet hypocotyls a few days after in vitro germination of seeds (Fig. 2d-h).

An analysis of the morphological parameters of plantlets grown in VC and NVC showed that, although fresh weight and the number of developed leaves were not statistically different, these parameters did tend to be lower in plantlets grown in closed containers at the end of the culture period. Park et al. (2004) reported that dry weight of in vitro cultured potato shoots was lower in completely sealed vessels where they became vitrified, than dry weight of shoots cultured in gas permeable vessels. In the case of plantlet height, differences were less obvious, but it was possible to observe that plantlets grown in NVCs were taller than plantlets cultured in VCs.

After $40 \mathrm{~d}$ of culture, the differences were more evident, particularly in their general physiological conditions. Plantlets maintained in NVCs showed a lower number of developed leaves, with intense chlorosis and persistent callus formation along the stem (Fig. 3a and b). Under these conditions, a faster senescence was observed with total leaf abscission. Despite these symptoms, plantlets remained alive, and their axillary buds emitted new shoots once the culture conditions were renovated (Fig. 3c and d). Plantlets grown in VCs grew vigorous, without the presence of callus, hyperhydration or leaf abscission (Fig. 3e and f).

Effect of cobalt chloride $\left(\mathrm{CoCl}_{2}\right)$ on ethylene production in Habanero pepper plantlets cultivated in NVCs. As shown in Fig. 4, ethylene concentrations in the headspace of the NVCs decreased when $\mathrm{CoCl}_{2}$ concentrations were increased. With these results it was possible

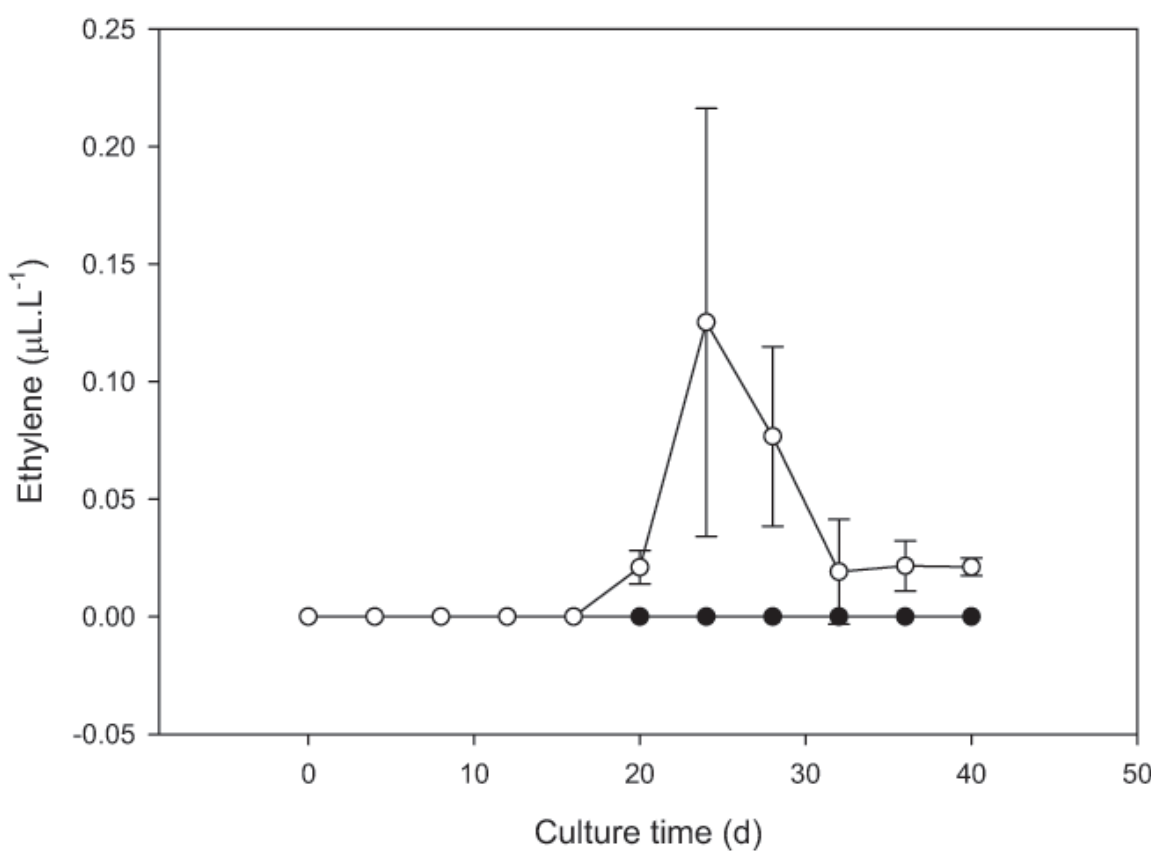

Fig. 1. Ethylene production in ventilated $(\bullet)$ and nonventilated $(\bigcirc)$ magenta boxes during in vitro culture of Habanero pepper shoots. Vertical bars represent $\pm \mathrm{SD}(\mathrm{n}=3)$. Data at days 20, 24, and 28 are statistically different according to the Student-Newman-Keuls Method $(P=0.0305)$.
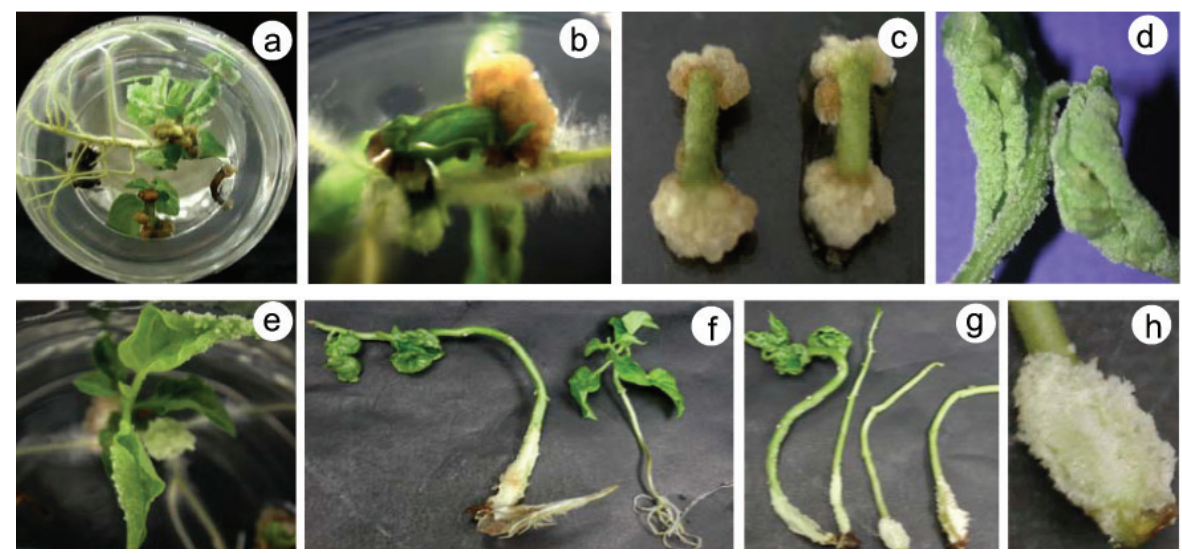

Fig. 2. Abnormalities observed during in vitro culture of Habanero pepper explants in nonventilated containers (MS medium without growth regulators): (a) Prominent formation of roots and nodules at the base of shoots; (b and c) Callus formation and presence of roots at the ends of nodal segments; (d-h) Callus formation (vitrification) at different parts of the plant and at different development stages. 
in the quality of the Habanero pepper plantlets was observed with the use of higher concentrations of this compound. However, in contrast with the $\mathrm{CoCl}_{2}$ treatments, ethylene production was higher and it was found to increase with higher concentrations of $\mathrm{AgNO}_{3}$ in the culture medium. The concentration of ethylene was considerably higher when a concentration of
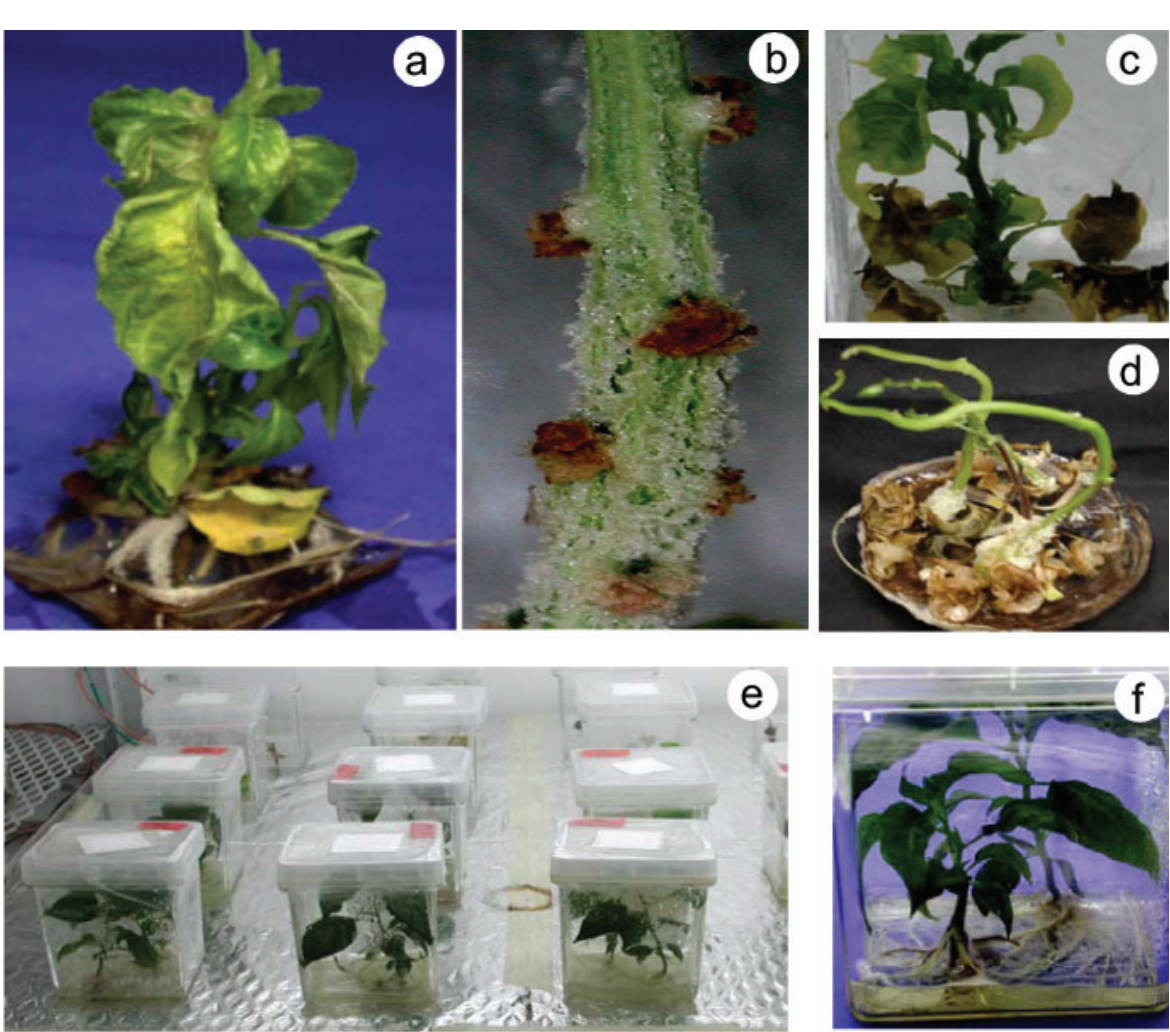

Fig. 3. Abnormalities observed during growth of Habanero pepper plantlets in nonventilated containers (MS medium without growth regulators): (a) chlorosis and leaf senescence, (b) callus formation along the stem; (c and d) leaf abscission until total defoliation of in vitro plantlets; (e and f) plantlets grown in ventilated containers. Vigor and leaf retention can be observed.

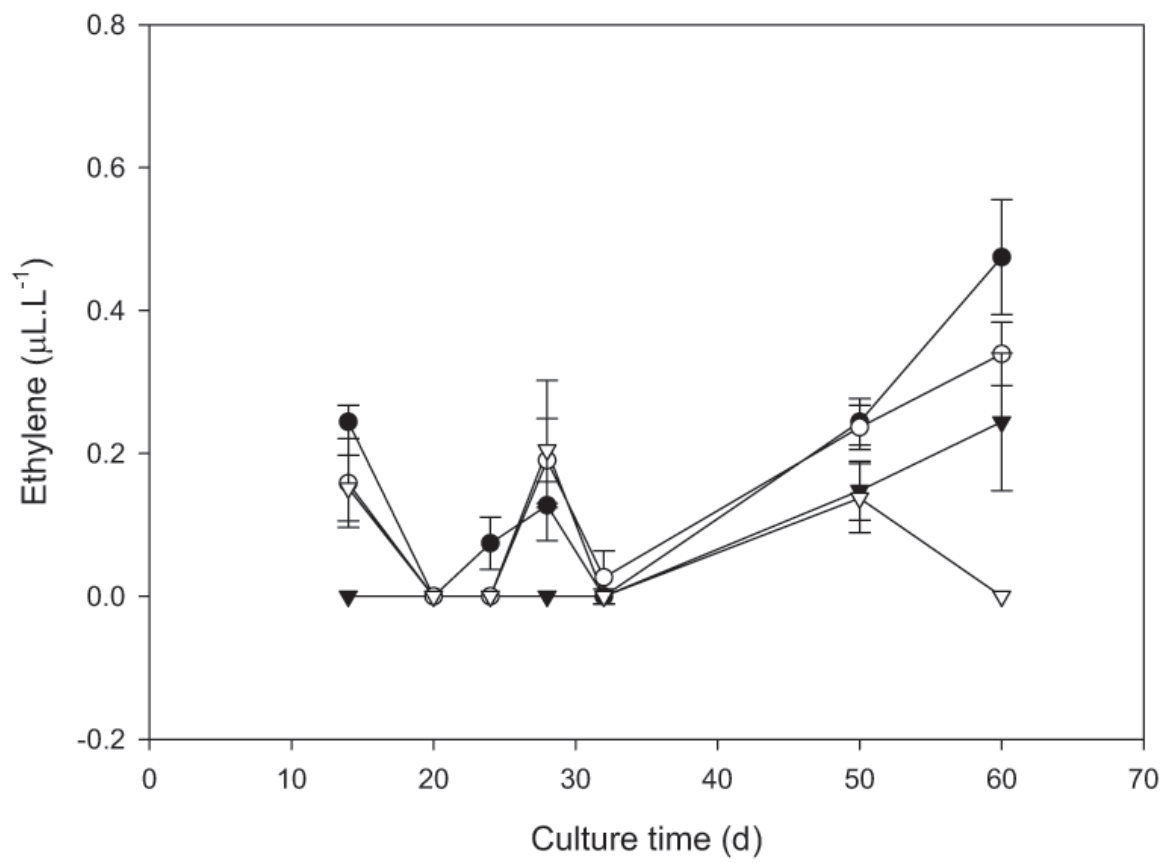

Fig. 4. Effect of cobalt chloride $\left(\mathrm{CoCl}_{2}\right)$ on ethylene production during Habanero pepper plantlets grown in vitro in nonventilated containers. $(\bullet) 0 \mu \mathrm{M} ;(\bigcirc) 50 \mu \mathrm{M} ;(\nabla) 300 \mu \mathrm{M} ;(\nabla) 500 \mu \mathrm{M}$. Vertical bars represent $\pm \operatorname{SD}(\mathrm{n}=3)$. plantlets also presented normal morphology, more vigor than the control plantlets, well developed roots, without occurrence of callus or hyperhydricity throughout the evaluation period (Fig. 7a). When $500 \mu \mathrm{M}$ of $\mathrm{AgNO}_{3}$ was used, the plantlets showed a lower incidence of ethiolation, longer internodes, intense chlorosis in the leaves, and less vigor (Fig. 7b).

These results show that the threshold accumulation of $\mathrm{Ag}^{+}$, which the Habanero pepper plantlets are able to tolerate without presenting symptoms of intoxication is between $\geq 300 \mu \mathrm{M}$ and $<500 \mu \mathrm{M} \mathrm{AgNO}_{3}$. In a preliminary test using concentrations of $\mathrm{AgNO}_{3}$ at $>300 \mu \mathrm{M}$, and different genotypes of Habanero pepper from a collection that is to be conserved in vitro, no differences were observed either among the genotypes or among the concentrations of ethylene inhibitor, and in general the physiological condition of the plantlets was optimal (data not shown).

On the other hand, it is obvious that $\mathrm{AgNO}_{3}$ did not inhibit ethylene production during in vitro culture of Habanero pepper, however, this effect was observed with the use of $\mathrm{CoCl}_{2}$ in the culture medium. $\mathrm{AgNO}_{3}$ can be used to protect the plantlets against the presence of ethylene in the atmosphere of the NVCs. The results obtained in this work confirm reports by Buddendorf and Woltering (1994), who stated that $\mathrm{Ag}^{+}$ions (from $\mathrm{AgNO}_{3}$ ) bind to ethylene receptors within the plant, avoiding any undesired effects. Similar results were obtained by Pua et al. (1993) who reported that the addition of $\mathrm{AgNO}_{3}$ during in vitro morphogenesis of Brassica oleracea resulted in higher levels of ethylene production.

\section{Discussion}

Ethylene accumulation in culture vessels is affected by the physical properties of the system (mainly the type of sealing) and the release by the plant material or other components in the system. The positive and negative effects of ethylene on the growth and development of in vitro cultured plants or explants have been demonstrated. Several reports indicate that ethylene production during in vitro culture can be implicated in cell differentiation and shoot or embryo regeneration (Cho and Kasha, 1989; Molina and Nuez, 1995; Pua and Chi, 1993; Vain et al., 1989). Callus formation can also be influenced by the level of ethylene (Biddington, 1992). It has also been reported that ethylene enhances shoot and root formation in some species, such as petunia (Dimasi-Theriou et al., 1993) and peach rootstock (Dimasi-Theriou and Economou, 1995). Nevertheless, there are also many crops extremely susceptible to ethyleneinduced in vitro. Vitrification, flaccidity, leaf sennescence, leafloss, abnormal stem swelling, necrosis, and other growth abnormalities have frequently been observed in potato microplant cultures during prolonged maintenance in vitro (López-Delgado et al., 1998; Sarkar and Naik, 1998; Sarkar et al., 1999). These morphological changes may be of such importance as to make it difficult, if not impossible, to regenerate a physiologically normal plant at the end of a storage period (Lizarraga et al., 1989). 
Our results demonstrate unequivocally that accumulated ethylene in the culture vessel causes severe physiological disorders during the in vitro culture of Habanero pepper, both in initial explants and in developing plantlets. In general, the effect of ethylene was detrimental during in vitro culture of Habanero pepper plantlets in closed containers. The persistance of callus formation in all organs of the plant could be interpreted as a very intense vitrification process. Further studies are obviously required to achieve a better understanding of the
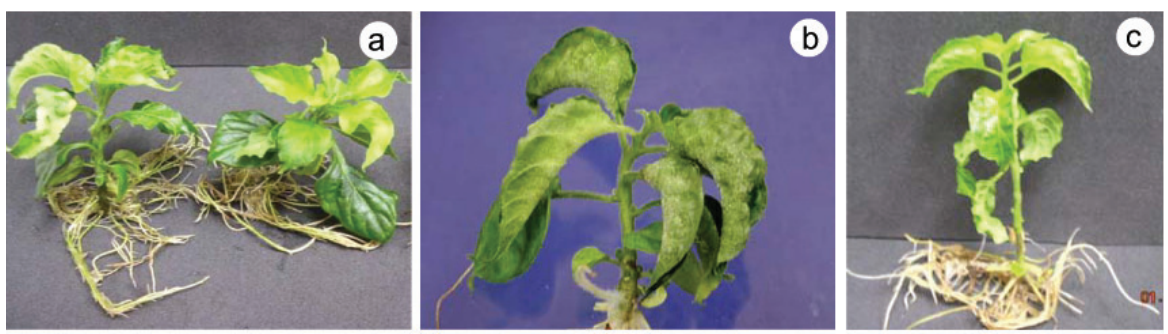

Fig. 5. Influence of $\mathrm{CoCl}_{2}$ concentration in ethylene effects on Habanero pepper plantlets. (a) Poor development of the plantlets at $50 \mu \mathrm{M}$. (b) Intensive callus formation along the stem and the leaves of the plantlet at $300 \mu \mathrm{M}$. (c) Ethiolated plantlets at $500 \mu \mathrm{M}$.

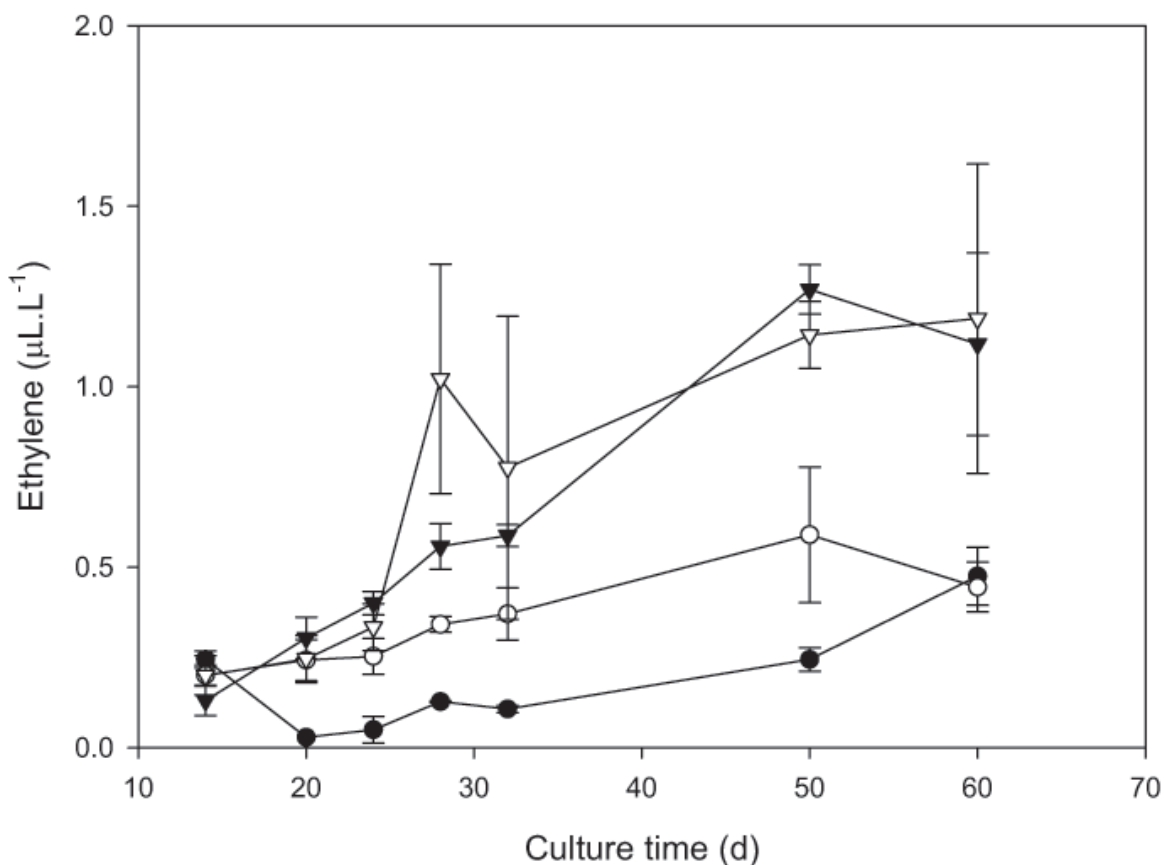

Fig. 6. Effect of silver nitrate $\left(\mathrm{AgNO}_{3}\right)$ on ethylene production during Habanero pepper plantlets cultured in vitro in nonventilated containers. ( $0 \mu \mathrm{M} ;(\bigcirc) 50 \mu \mathrm{M} ;(\boldsymbol{\nabla}) 300 \mu \mathrm{M} ;(\nabla) 500 \mu \mathrm{M}$. Vertical bars represent $\pm \operatorname{SD}(\mathrm{n}=3)$.
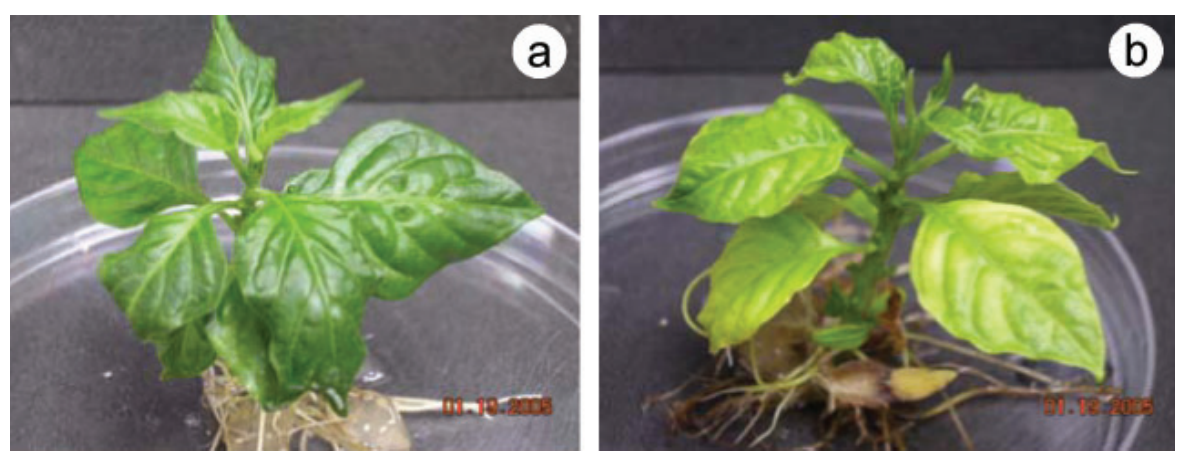

Fig. 7. Influence of $\mathrm{AgNO}_{3}$ in ethylene effects on Habanero pepper plantlets. (a) Healthy plantlets at 300 $\mu \mathrm{M}$. (b) Chlorosis at $500 \mu \mathrm{M}$. tion and, hence, accumulation in the vessel. However, once produced, ethylene is thought to bind to a receptor protein which mediates the response. The binding of ethylene to the receptor can be blocked by $\mathrm{Ag}^{+}$ions, applied as $\mathrm{AgNO}_{3}$ or silver thiosulphate (STS). Silver ion $\left(\mathrm{Ag}^{+}\right)$inhibits ethylene action by substituting for $\mathrm{Cu}^{+}$at the active site of the ethylene receptor (Beyer, 1979). This indicates that the action of silver would result in a decrease in the number of functional receptors, inferring a noncompetetive type of inhibition. The results of this study demonstrated that, although the addition of $\mathrm{AgNO}_{3}$ to the culture medium did not inhibit ethylene production, the growth and development of the plantlets were normal and vigorous. In contrast, when $\mathrm{CoCl}_{2}$ was used as an ethylene inhibitor it was effective in reducing ethylene concentration inside the vessels, but did not have a positive effect on the development and quality of the plantlets, as described in the results. This could be attributed to the deficit or displacement effect of iron and copper caused by the cobalt and manifested in a toxic effect on the plant in the form of an increase in the number of chlorotic leaves which then become necrotic and wither. These symptoms can be observed in this study as well as the presence of callus in all areas of the plantlet.

With these results, it is possible therefore, to recommend the use of $\mathrm{AgNO}_{3}$ as an ethylene inhibitor, and the use of VCs without ethylene inhibitors, but only during the regeneration and multiplication in vitro of Habanero pepper, as these are processes in which subcultures are frequently carried out. In both conditions, shoots and plantlets showed a normal, vigorous development. In the case of the silver nitrate treatment, it would be convenient to carry out an evaluation of its effect, particularly toxicity, on cell, tissue and/or plantlet cultures during prolonged maintenance in vitro.

The results obtained in this study are undoubtedly of considerable relevance and should prove useful in the advancement of much research currently being carried out on this species, but it is not enough. The presence and effect of ethylene still represent a serious threat for the in vitro conservation and regeneration of Habanero pepper plantlets by indirect morphogenesis (somatic embryogenesis and/or organogenesis), particularly from cell suspensions.

Some reports indicate a marked increase in the production of ethylene during the conservation through minimum or slow growth, due to the fact that the plantlets are maintained under intense physiological stress (osmotic stress, low temperatures, and low light intensity) (Sarkar et al., 2002). It is important to point out that the VCs require more frequent renewal of the culture medium due to greater water loss in comparison with the NVCs. This could be a disadvantage during the in vitro conservation.

With these results we can also infer that the Habanero pepper is probably one of the plant species most sensitive to the ethylene produced and accumulated during in vitro culture. The dramatic effect of ethylene on in 
vitro growth and development of Habanero pepper is clear evidence of the fact. Ethylene may be one factor providing an important contribution to the recalcitrant morphogenesis of the Capsicum genus. Some of these aspects are under study at present in our laboratory, as part of an ongoing research project, the aim of which is the in vitro conservation and genetic improvement of Habanero pepper.

\section{Literature Cited}

Auboiron, E., M.P. Carron, and N. Michaux-Ferriere. 1990. Influence of atmospheric gases, particularly ethylene on somatic embryogenesis of Hevea brasiliensis. Plant Cell Tiss. Org. Cult. 21:31-37.

Beyer,E.M. 1979. Effect of silver ion, carbon dioxide and oxygen on ethylene action and metabolism. Plant Physiol. 63:169-173.

Biddington, N.L. 1992. The influence of ethylene in plant tissue culture. Plant Growth Regulat $11: 173-178$

Blankenship, S.M., D.A. Bailey, and J.E. Miller 1993. Effects of continuous, low levels of ethylene on growth and flowering of Easter lily. Scientia Hort. 53:311-317.

Buddendorf-Joosten, J.M.C. and E.J. Woltering. 1994. Components of the gaseous environment and their effects on plant growth and development in vitro, p. 165-190. In: P.J. Lumsden, J.R Nicholas, and W.J. Davies (eds.). Physiology, growth and development of plants in culture. Kluwer Academic Publishers, Dordrecht, The Netherlands.

Chi, G-L., D.G. Barfield, G-E. Sim, and E-C. Pua 1990. Effect of $\mathrm{AgNO}_{3}$ and aminoethoxyvinylglycine on in vitro shoot and root organogenesis from seedling explants of recalcitrant Brassica genotypes. Plant Cell Rpt. 9:195-198.

Chi, G-L., and E-C. Pua. 1989. Ethylene inhibitors enhanced de novo shoot regeneration from cotyledons of Brassica campestris ssp. chinensis (chinese cabbage) in vitro. Plant Sci. 64:243-250.

Chi, G-L., E-C. Pua, and C-J Goh. 1991. Role of ethylene on de novo shoot regeneration from cotyledons of Brassica campestris ssp. pekinensis (Lour) olsson in vitro. Plant Physiol. 96:178-183.

Cho, U.H., and J.K. Kasha. 1989. Ethylene production and embryogenesis from anther cultures of barley (Hordeum vulgare). Plant Cell Rpt. 10:204-207.

Chraibi, B.K.M., A. Latche, J-P. Roustan, and J. Fallot. 1991. Stimulation of shoot regeneration from cotyledon of Helianthus annuus by the ethylene inhibitors, silver and cobalt. Plant Cell Rpt. 8:415-417.

Dimasi-Theriou, K. and A.S. Economou. 1995. Ethylene enhances shoot formation in cultures of the peach rootstock GF-677 (Prunus persica x P. Amygdalus). Plan Cell Rep. 15:87-90.

Dimasi-Theriou, K., A.S. Economou, and E.M. Sfakiotakis. 1993. Promotion of petunia (Petunia hybrida L.) regeneration in vitro by ethylene. Plant Cell Tiss. Org. Cult. 32:219-225.

Finkelstein, R., M. Estelle, J. Martínez-Zapater, and C. Sommerville. 1988. Arabidopsis as a tool for the identification of genes involved in plant development, p. 7-25. In: D.P.S. Verma and R.B. Deberg (eds.). Plant gene research. Springer-Verlag Wien New York.

Lizarraga, R., Z. Huaman, and J.H. Dodds. 1989. In vitro conservation of potato germplasm at the International Potato Centre. Amer. Potato J. 66:253-269.

Lopez-Delgado, H., M. Jimenez-Casas, and I.M. Scott. 1998. Storage of potato microplants in vitro in the presence of acetylsalicilic acid. Plant Cell Tiss. Org. Cult. 54:145-152.

Mohiuddin, A.K.M., M.K.U. Chowdhury, Z.C. Abdullah, and S. Napis. 1995. The influence of cobalt chloride on in vitro shoot proliferation in cucumber (Cucumis sativus L.). Asian Pacific J. Mol. Biol. Biotechnol. 3(4):332-338.

Mohiuddin, A.K.M., M.K.U. Chowdhury, Z.C. Abdullah, and S. Napis. 1997. Influence of silver nitrate (ethylene inhibitor) on cucumber in vitro shoot regeneration. Plant Cell Tiss. Org. Cult. 51:75-78.

Molina, R.V. and F. Nuez. 1995. Characterization and classification of different genotypes in a population of Cucumis melo based on their ability to regenerate shoots from leaf explants.
Plant Cell Tiss. Org. Cult. 43:249-257.

Murashige, T. and F. Skoog. 1962.Arevised medium for rapid growth and bioassays with tobacco tissue culture. Physiol. Plant. 15:473-497.

Palmer, C.E. 1992. Enhanced shoot regeneration from Brassica campestris by silver nitrate. Plant Cell Rpt. 11:541-545.

Park, S.W., J. H. Jeon, H.S. Kim, Y.M. Park, C. Aswath, and H. Joung. (2004). Effect of sealed and vented gaseous microenvironments on the hyperhydricity of potato shoots in vitro. Scientia Hort. 99(2):199-205.

Pua, E-C. 1993. Cellular and molecular aspects of ethylene on plant morphogenesis of recalcitrant Brassica species in vitro. Bot. Bul. Acad. Sin. 34:191-209.

Pua, E-C. and G-L. Chi. 1993. De novo shoot morphogenesis and plant growth of mustard (Brassicajuncea) in vitro in relation to ethylene. Physiol. Plant. 88:467-474.

Robinson, E.P. and D.O. Adams. 1987. The role of ethylene in the regeneration of Helianthus annuus (sunflower) plants form callus. Physiol. Plant. 71:151-156.

Santana-Buzzy, A. Canto-Flick, F. Barahona-Pérez, M.C. Montalvo-Peniche, P.Y. Zapata-Castillo, A. Solís-Ruiz, A. Zaldívar-Collí, O. GutiérrezAlonso, and M.L. Miranda-Ham. Regeneration of Habanero pepper (Capsicum chinense Jacq.) via organogenesis. 2005. HortScience 40(6):1829-1831.

Sarkar, D. and P.S. Naik. 1998. Factors affecting minimal growth conservation of potato microplants in vitro. Euphytica. 102:275-280.

Sarkar, D., S.K. Kaushik, and P.S. Naik. 1999. Minimal growth conservation of potato microplants: Silver thiosulfate reduces ethylene-induced growth abnormalities during prolonged storage in vitro. Plant Cell Rpt. 18(11):897-903.

Vain, P., H. Yean, and P. Flament. 1989. Enhancement of production and regeneration of embryogenic type II callus in Zea mays L. by $\mathrm{AgNO}_{3}$. Plant Cell Tiss. Org. Cult. 18:143-151.

Wheeler, R.M., B.V. Peterson, and G.W. Stutte. 2004. Ethylene production throughout growth and development of plants. HortScience 39:1541-1545. 